\title{
Biomechanical properties of the thoracic aorta in Marfan patients
}

\author{
Fatiesa Sulejmani ${ }^{1}$, Anastassia Pokutta-Paskaleva ${ }^{1}$, Bulat Ziganshin ${ }^{2}$, Bradley Leshnower ${ }^{3}$, Glen Iannucci $^{4}$, \\ John Elefteriades ${ }^{2}$, Wei Sun ${ }^{1}$
}

${ }^{1}$ The Wallace H. Coulter Department of Biomedical Engineering, Georgia Institute of Technology and Emory University, Atlanta, GA, USA; ${ }^{2}$ Aortic Institute of Yale-New Haven Hospital, New Haven, CT, USA; ${ }^{3}$ Division of Cardiothoracic Surgery, ${ }^{4}$ Sibley Heart Center Cardiology, Emory University School of Medicine, Atlanta, GA, USA

Correspondence to: Wei Sun, PhD. The Wallace H. Coulter Department of Biomedical Engineering, Georgia Institute of Technology and Emory University, Technology Enterprise Park, Room 206, 387 Technology Circle, Atlanta, GA, USA. Email: wei.sun@bme.gatech.edu.

Background: Marfan syndrome (MFS), a genetic disorder of the connective tissue, has been strongly linked to dilation of the thoracic aorta, among other cardiovascular complications. As a result, MFS patients frequently suffer from aortic dissection and rupture, contributing to the high rate of mortality and morbidity among MFS patients. Despite the significant effort devoted to the investigation of mechanical and structural properties of aneurysmal tissue, studies on Marfan aneurysmal biomechanics are scarce. Ex vivo mechanical characterization of MFS aneurysmal tissue can provide a better insight into tissue strength outside the physiologic loading range and serve as a basis for improved risk assessment and failure prediction.

Methods: The mechanical and microstructural properties of MFS aneurysmal thoracic aorta (MFS, $\mathrm{n}=15$, $39.5 \pm 3.91$ years), non-MFS aneurysmal thoracic aorta (TAA, $n=8,52.8 \pm 4.9$ years), healthy human thoracic aorta $(\mathrm{HH}, \mathrm{n}=8,75.4 \pm 6.1$ years), and porcine thoracic aorta $(\mathrm{n}=10)$ are investigated. Planar biaxial tensile testing and uniaxial failure testing were utilized to characterize the mechanical and failure properties of the tissue, respectively. Verhoeff-Van Gieson (VVG) and PicroSirius Red stains were utilized to visualize the elastin and collagen fiber architecture, respectively.

Results: MFS tissue was found to have age-dependent but diameter-independent mechanical, structural, and morphological properties, also showing extensive elastin fiber degradation. Non-MFS thoracic aneurysmal aorta was thicker and stiffer than age-matched MFS tissue. Moreover, non-MFS thoracic aneurysmal mechanics resembled closely the mechanics of older healthy human tissue. Younger MFS tissue ( $<40$ years) exhibited similar mechanical and structural properties to aged porcine tissue.

Conclusions: Both age and aneurysmal presence were found to be factors associated with increased stiffness in aortic tissue, and aortic diameter was not a significant determinant of mechanical property deterioration. Additionally, the presence of MFS was found to induce stiffening of the thoracic aorta, although not to the extent of the non-MFS aneurysm.

Keywords: Marfan syndrome (MFS); thoracic aortic aneurysm; aortic dilation; aortic stiffening; vascular mechanics

Submitted Jun 26, 2017. Accepted for publication Sep 04, 2017.

doi: 10.21037/acs.2017.09.12

View this article at: http://dx.doi.org/10.21037/acs.2017.09.12

\section{Introduction}

Marfan syndrome (MFS) is a multisystemic disorder of the connective tissue with no predilection for either sex or race, primarily affecting the cardiovascular, ocular, and skeletal systems. Occurring in 2-3 per 10,000 individuals (1), MFS cases are primarily caused by a mutation of the elastinforming FBN1 gene, leading to reduced tissue strength, loss of cell-matrix interactions, and phenotypic irregularities of MFS patients (2).

Cardiovascular complications are the most common feature of MFS, including dilation of the aorta and main pulmonary 
artery, thickening and prolapse of the atrioventricular valves, aortic valve regurgitation, and mitral valve prolapse (2). Progressive dilatation of the aortic root and subsequent aortic dissection and rupture is the leading cause of premature death in MFS patients (3).

Due to improved awareness, presymptomatic monitoring, and advances in treatments, the medial life expectancy for patients with MFS has risen from the reported 45 years in 1972 (4) to 72 years in 1995 (5). Nonetheless, diagnosing MFS is challenging, especially in patients with no or uncertain family history. The revised Ghent scoring criteria incorporate a comprehensive clinical assessment of multiple systems, with major weight given to aortic root aneurysm and ectopia lentis, and molecular genetic screening for mutations in the FBN1 gene (6). Additionally, the Ghent system highlights the age of 40 years in the evaluation of cardiovascular complications (1).

Despite the significant improvements in the treatment and diagnosis of MFS, this condition remains associated with a high premature mortality and morbidity (1). Notwithstanding the advances in MFS diagnosis and treatment, patientspecific risk factors for premature aortic dilation and rupture or interventions based on individual tissue characteristics are lacking.

It is known that MFS patients are at a higher risk for development of thoracic aortic aneurysms as compared to abdominal aneurysms (7); nonetheless, the former have been less extensively studied, particularly in the context of MFS. Previous studies have investigated the mechanical and structural properties of MFS thoracic aortic aneurysmal tissue both in vivo and ex vivo, consistently showing a decrease in aortic distensibility, increase of stiffness index, and increase in aortic size with dilation (3,8-15). However, in vivo studies are limited to the investigation of the physiological range of pressures and thus are unable to characterize the possibility of adverse events, such as aortic dissection and rupture potential. Comprehensive mechanical studies are therefore necessary for the thorough understanding of the mechanical behavior of MFS aortas, which, when coupled with patient-specific geometry and loading conditions, can provide insight into the risk of adverse events on a patient-by-patient basis.

The objective of the present study is to characterize the MFS tissue mechanical and microstructural properties in order to provide a basis for rigorous mathematical and computational modeling of the MFS aortic mechanics. Healthy human $(\mathrm{HH})$ aortic tissue, along with thoracic aortic aneurysmal tissue in both the Marfan and non-Marfan
(TAA) context are subjected to planar biaxial tensile testing, uniaxial failure testing, and histological analysis in order to capture the separate contributions of the aneurysmal and Marfan conditions to the mechanics and structure of the thoracic aorta. Additionally, the roles of aging and aortic dilation on the mechanical and structural properties of both healthy and MFS tissue are investigated.

\section{Methods}

\section{Patient data}

Thoracic aortic samples from MFS patients $(n=15)$ were obtained from Yale University after explantation from a composite graft replacement procedure $(\mathrm{n}=12)$, ascending aorta replacement $(\mathrm{n}=1)$, or ascending aorta replacement with aortic valve replacement $(n=2)$. All patients suffered from a thoracic aortic aneurysm, two of which also suffered aortic dissection. Of the 15 patients, 3 had a bicuspid aortic valve. MFS patients were $39.5 \pm 3.91$ years old, on average, ranging from 18 to 63 years of age, and consisting of seven females and eight males. MFS patients were separated into two age groups, age less than 40 years (MFS Young) and age greater than 40 years (MFS Old) based on the Ghent scoring criteria.

Human hearts were obtained from the National Disease Research Interchange (NDRI, Philadelphia, PA, USA). The hearts were fresh frozen within a post-mortem recovery interval of 24 hours, aortas were explanted and cryopreserved, and kept frozen until testing. Patients were included based on the lack of cardiovascular diseases, and thus considered "healthy" for the purposes of this study. Human patients $(\mathrm{n}=10)$ consisted of 9 females and 1 male, averaging $75.4 \pm 6.1$ years. Sixty-five years was used as a cut off age to separate the human group into Healthy Human Young $(54.0 \pm 2.52)$ and Healthy Human Old $(84.4 \pm 4.8)$ according to AHA guidelines (16).

Thoracic aortic samples from non-MFS patients $(n=9)$ were obtained from Emory University Hospital after explantation and cryopreserved within 24 hours of surgery. All patients suffered from a thoracic aortic aneurysm, five of which also suffered aortic dissection. Of the 9 patients, 1 also had a bicuspid aortic valve. Patients were, on average, $52.8 \pm 4.9$ years old, ranging from 30 to 69 years of age, and consisting of 6 males and 3 females.

Porcine hearts were obtained fresh from the local abattoir (Holifield Farms, Covington, GA, USA), ranging between 1 and 5 years of age. The ascending aorta was explanted and 

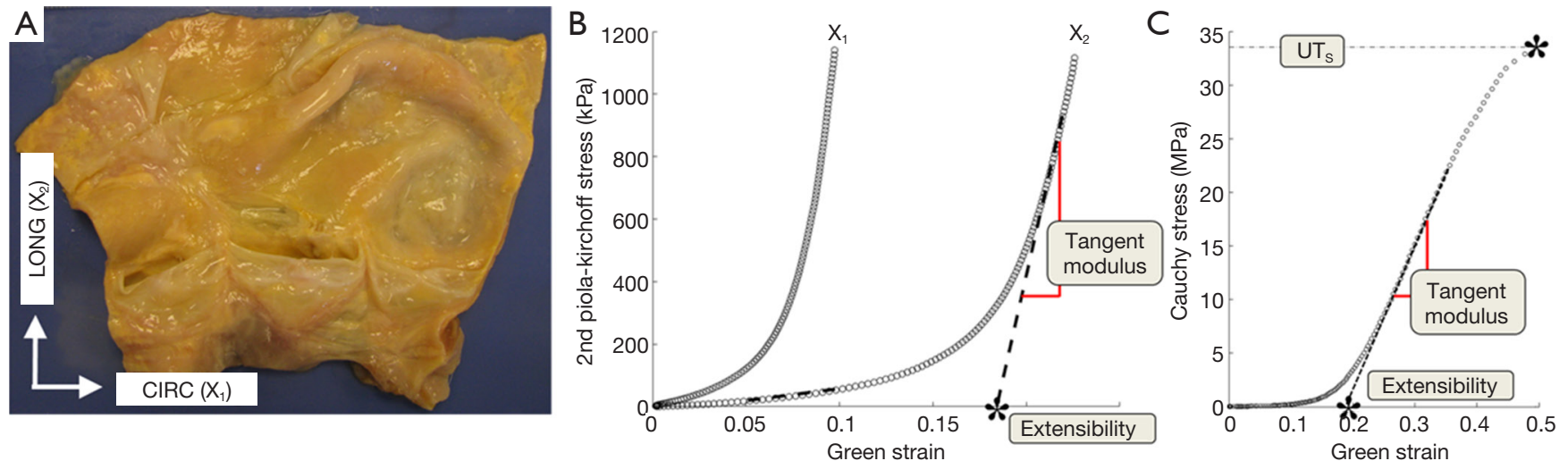

Figure 1 Methods. (A) Representative aorta sample from the HH (healthy human) group, depicting the circumferential and longitudinal directions; (B) representative equibiaxial response, showing calculations for the tangent modulus and extensibility; (C) representative uniaxial response, showing ultimate tensile stress (UTS), tangent modulus, and extensibility. *, indicates point of interest.

cryopreserved until testing could be performed.

The use of human tissues was approved by the Institutional Review Board at the Georgia Institute of Technology. Samples were cryopreserved in a $90 \% / 10 \%$ RPMI-1640/DMSO solution upon explantation and stored at $-80{ }^{\circ} \mathrm{C}$ until testing could be performed.

\section{Biaxial testing}

Planar biaxial tensile testing was conducted according to the methods described by Sacks and Sun (17). Briefly, a square section of the aortic sample was cut such that the $X_{1}$ axis corresponded with the circumferential direction and $\mathrm{X}_{2}$ with the longitudinal (Figure 1). Thickness was measured and averaged in three distinct locations throughout the testing region using a Mitutoyo 7301 rotating thickness gage (Aurora, $\mathrm{IL}, \pm 0.01 \mathrm{~mm}$ resolution).

A square region was delimited by 16 suture hooks, 4 per side. Four graphite markers were fixed to the center of the tissue for strain tracking. The sample was mounted onto a testing machine in a trampoline-like fashion, submerged in a $0.9 \%$ saline solution maintained at $37^{\circ}$ Celsius for the duration of the test, and subjected to a stress-controlled testing protocol. The ratio of the normal Lagrangian stress components $\mathrm{P}_{11}: \mathrm{P}_{22}$ was predefined with shear terms $\mathrm{P}_{12}=\mathrm{P}_{21}=0$. Samples were subjected to a minimum of 30 equibiaxial preconditioning cycles to minimize hysteretic effects and ensure repeatability of the mechanical response, which were followed by seven testing protocols, with $\mathrm{P}_{11}: \mathrm{P}_{22}=1: 1,0.75: 1,0.5: 1,0.3: 1,1: 0.75,1: 0.5,1: 0.3$.

\section{Uniaxial testing}

Uniaxial testing samples adjacent to the biaxial samples were carefully cut into a "dog-bone" shape to ensure failure in the center of the testing region and minimize grip effects. Each sample was aligned with the circumferential axis. Graphite markers were fixed along the sample for strain tracking. The axial force was measured by means of a $500 \mathrm{lbf}$ load cell (TestResources SM-500-294). Samples were clamped onto the machine and subjected to ten preconditioning cycles before loading at a rate of $50 \mathrm{~mm} / \mathrm{min}$ until failure. Samples were continuously hydrated with saline solution throughout testing.

\section{Histology}

Two histological specimens (circumferentially and longitudinally aligned) were cut from the biaxial samples ( $\mathrm{n}=3$ per testing group), fixed in $10 \%$ formalin for at least 24 hours, processed, and embedded in paraffin. Samples were sectioned into $7 \mu \mathrm{m}$-thick slices, and subjected to Verhoeff Van-Gieson (VVG) and PicroSirius Red stains. Analysis of tissue microstructure was performed with the Zeiss Axio Scope.A1 polarized light microscope and collection of images taken at $5 \times, 10 \times, 20 \times$, and $40 \times$ magnification levels were processed with the Zeiss Zen imaging software. The VVG slides show both collagen (pink) and elastic fibers (black); PicroSirius Red slides are imaged using circularly polarized light showing newer, thinner collagen fibers as green, and older, thicker fibers as red/orange. 


\begin{tabular}{llll}
\multicolumn{2}{l}{ Table 1 General patient characteristics } & Aortic size (mm) & Aortic thickness (mm) \\
\hline Group & Age (years) & $47 \pm 2.06$ & $1.70 \pm 0.07$ \\
\hline MFS (young) & $28.5 \pm 3.4$ & $52 \pm 3.21$ & $1.87 \pm 0.12$ \\
MFS (old) & $53.3 \pm 3.7$ & $63 \pm 7.49$ & $2.25 \pm 0.13$ \\
TAA & $52.8 \pm 4.9$ & - & $2.07 \pm 0.12$ \\
Healthy human & $75.4 \pm 6.1$ & - & $2.86 \pm 0.10$ \\
Porcine & $1-5$ & &
\end{tabular}

\section{Data analysis}

Patient age, tissue thickness, and aortic size were obtained from each patient group. All results are presented as mean \pm standard error. Aortic size was not available for the healthy human and porcine groups. All biaxial plots show Green Strain, calculated as $E=\frac{1}{2}\left(F^{T} F-1\right)$, and Second PiolaKirchoff Stress, calculated as $S=F^{-1} \frac{f}{h L}$, where $F$ is the deformation gradient, $f$ is the current force value in the circumferential and longitudinal directions, $h$ and $L$ are the initial unloaded thickness and length, respectively. From the biaxial tensile testing data, stiffness was quantified by means of the tangent modulus (TM) in both the low and high linear regions of the equibiaxial response curve (Figure 1). The data points within each region were fitted in the least-square sense by means of a custom MATLAB code (MathWorks, Natick, MA, USA). TM was calculated from the slope of the fitted line, and extensibility was defined as the intersection of the fitted line from the high linear region with the $\mathrm{X}$-axis. The degree of anisotropy (DA) was quantified as the ratio of the maximum strains reached in the equibiaxial response. Additionally, ultimate tensile stress (UTS) and extensibility were quantified from the uniaxial response.

All results were tested for normality of distribution using the Kolmogorov-Smirnoff test. Normally distributed results were compared by use of the unpaired student's $t$-test, while the Wilcoxon rank-sum test was utilized for non-parametric results. $P$ values less than 0.05 were considered significant.

\section{Results}

\section{General results}

Table 1 shows the general patient and morphological characteristics of each testing group. The healthy human patients were on average at least 20 years older than the other human groups. TAA and MFS Old patients were of similar age.

Figure 2 shows the averaged equibiaxial mechanical response (A) and the averaged biaxially-derived mechanical properties of all groups (B-E). All samples exhibited nonlinear, anisotropic stress-strain responses, with the circumferential direction less extensible than the longitudinal. It is important to note that each group reached a different equibiaxial stress level, with the MFS Young and porcine tissue reaching $\geq 150 \mathrm{kPa}$, the TAA tissue $\geq 120 \mathrm{kPa}$, the aged human $\geq 100 \mathrm{kPa}$, and the MFS Old tissue $\sim 90 \mathrm{kPa}$.

In general, the aged healthy human tissues were found to exhibit the stiffest response, both in the low and high region of the mechanical response curves, along both testing directions. In the low linear region of the curve, all remaining groups exhibited similar stiffnesses, while in the high region, the healthy human and MFS Young patients exhibited the highest circumferential stiffness and the healthy human and MFS Old tissue exhibited the highest longitudinal stiffness. The porcine tissue was the most compliant of all groups. Similarly, the MFS Young and porcine tissue had the highest extensibility; the TAA and aged human tissue had the lowest. MFS Old and aged human tissue were found to exhibit the most isotropic equibiaxial response, while MFS Young, TAA, and porcine tissue were more anisotropic. All parameters are also summarized in Table 2 for each testing group.

Figure 3 shows the uniaxial responses of representative samples from each testing group (A), as well as the UTS (B) and extensibility $(\mathrm{C})$ of each sample. The MFS Old sample had the lowest UTS value, at $0.63 \mathrm{MPa}$, followed by the aged $\mathrm{HH}(1 \mathrm{MPa})$, MFS Young (1.2 MPa), TAA (1.95 MPa), and porcine (3.3 MPa). The MFS Young, TAA, and porcine 
B

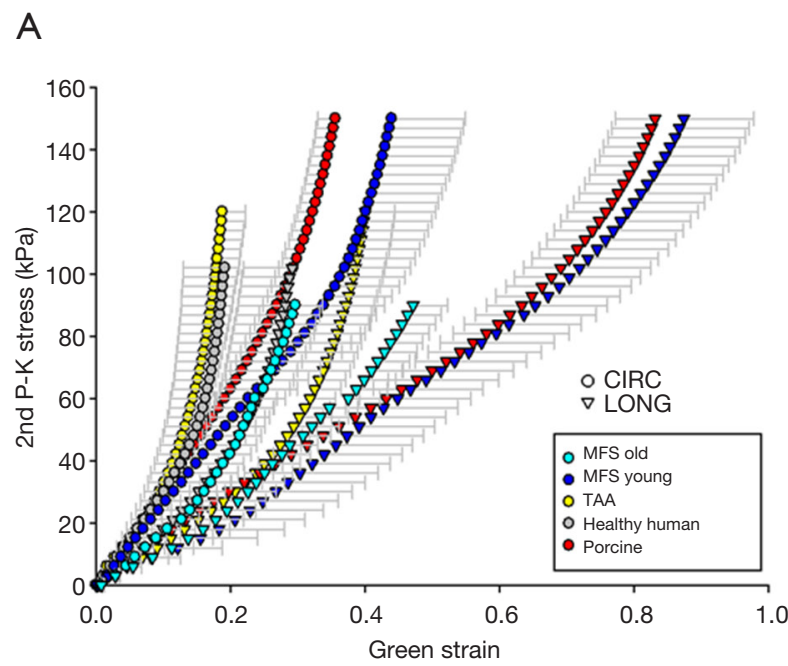

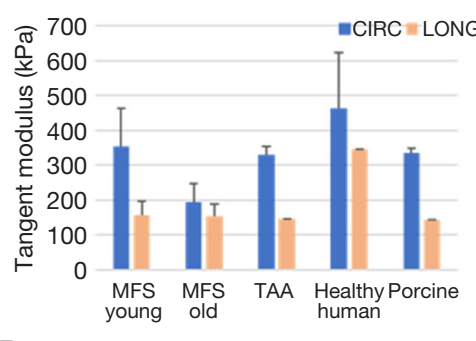

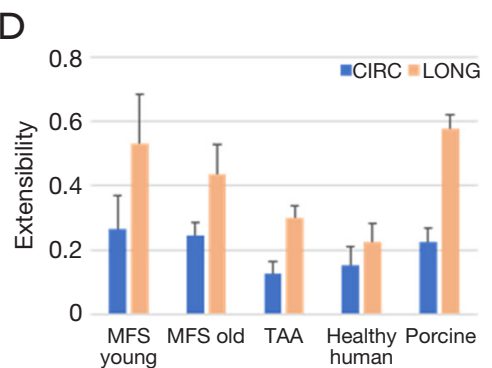

C

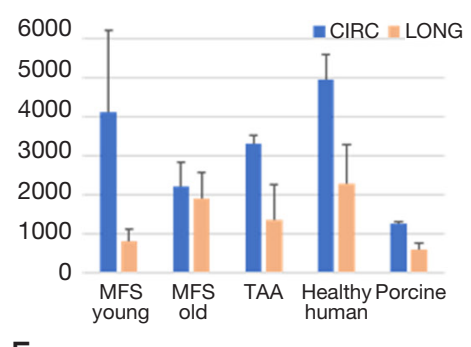

$\mathrm{E}$

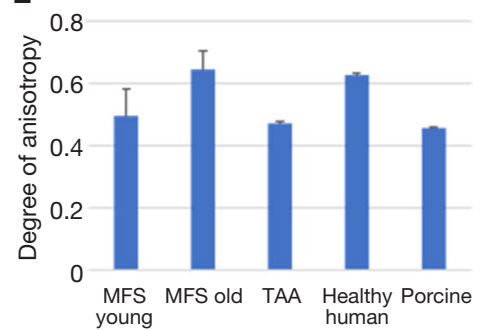

Figure 2 Summary of biaxial results. (A) Average equibiaxial response \pm standard error for each testing group; (B) low tangent modulus for each group along the circumferential (blue) and longitudinal (orange) directions; (C) high tangent modulus for each group along the circumferential (blue) and longitudinal (orange) directions; (D) extensibility for each group along the circumferential (blue) and longitudinal (orange) directions; (E) degree of anisotropy measurements for each group, on a scale of 0 (perfectly anisotropic) to 1 (perfectly isotropic). MFS Old, Marfan syndrome with thoracic aortic aneurysm > 40 years; MFS Young, Marfan syndrome with thoracic aortic aneurysm < 40 years; TAA, non-Marfan thoracic aortic aneurysm; Healthy human (HH), human thoracic aortic tissue without known cardiovascular disease; Porcine, Porcine thoracic aortic tissue without known cardiovascular disease.

\begin{tabular}{|c|c|c|c|c|c|}
\hline Parameter & MFS Young & MFS Old & TAA & Healthy human & Porcine \\
\hline Sample size & 7 & 7 & 8 & 8 & 10 \\
\hline Age (years) & $28.50 \pm 3.36$ & $53.29 \pm 2.69$ & $52.80 \pm 4.89$ & $75.44 \pm 6.05$ & $1-5$ \\
\hline Aortic size $(\mathrm{mm})$ & $46.70 \pm 2.06$ & $52.43 \pm 3.21$ & $62.80 \pm 7.49$ & - & - \\
\hline Thickness (mm) & $1.70 \pm 0.07$ & $1.87 \pm 0.12$ & $2.24 \pm 0.17$ & $2.07 \pm 0.12$ & $2.86 \pm 0.10$ \\
\hline EXT long & $0.43 \pm 0.09$ & $0.43 \pm 0.09$ & $0.30 \pm 0.04$ & $0.22 \pm 0.06$ & $0.58 \pm 0.04$ \\
\hline EXT circ & $0.25 \pm 0.04$ & $0.25 \pm 0.04$ & $0.13 \pm 0.02$ & $0.15 \pm 0.06$ & $0.23 \pm 0.04$ \\
\hline DA & $0.50 \pm 0.90$ & $0.64 \pm 0.06$ & $0.47 \pm 0.06$ & $0.63 \pm 0.01$ & $0.46 \pm 0.00$ \\
\hline TM long low (kPa) & $155.59 \pm 42.11$ & $154.62 \pm 35.14$ & $147.07 \pm 23.26$ & $345.74 \pm 0.05$ & $142.84 \pm 0.02$ \\
\hline TM long high (kPa) & $803.15 \pm 316.40$ & $1,917.57 \pm 653.97$ & $1,367.28 \pm 218.81$ & $2,293.74 \pm 0.07$ & $611.70 \pm 0.04$ \\
\hline TM circ low (kPa) & $353.65 \pm 109.42$ & $193.97 \pm 54.33$ & $329.73 \pm 89.44$ & $462.72 \pm 161.12$ & $336.24 \pm 12.62$ \\
\hline TM circ low (kPa) & $353.65 \pm 109.42$ & $193.97 \pm 54.33$ & $329.73 \pm 89.44$ & $462.72 \pm 161.12$ & $336.24 \pm 12.62$ \\
\hline
\end{tabular}

MFS, Marfan syndrome; TAA, non-Marfan thoracic aortic aneurysm; EXT, extensibility; circ, circumferential direction; long, longitudinal direction; DA, degree of anisotropy; TM, tangent modulus. 

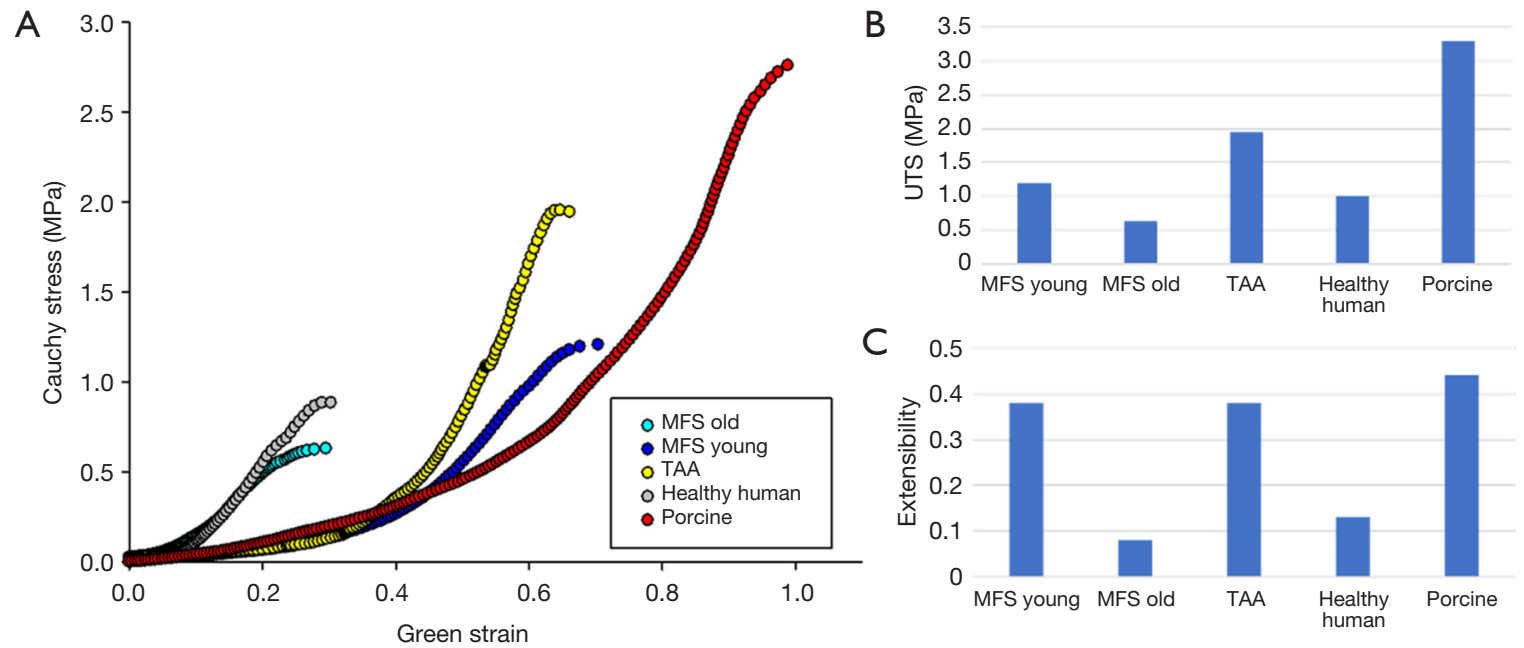

Figure 3 Summary of uniaxial results. (A) Representative uniaxial response for each testing group; (B) ultimate tensile stress (UTS) for each representative sample; (C) extensibility for each representative sample. MFS Old, Marfan syndrome with thoracic aortic aneurysm $>40$ years; MFS Young, Marfan syndrome with thoracic aortic aneurysm <40 years; TAA, non-Marfan thoracic aortic aneurysm; Healthy human (HH), human thoracic aortic tissue without known cardiovascular disease; Porcine, Porcine thoracic aortic tissue without known cardiovascular disease.

groups had similar extensibility $(0.38,0.38$, and 0.44$)$, while the MFS Old and aged human had extensibilities of 0.08 and 0.13 , respectively.

Figures 4 and 5 show representative VVG and PicroSirius images, respectively for all testing groups, at $20 \times$ magnification. Histological results are separately addressed in the coming sections.

\section{Marfan tissue exhibits age-dependent mechanical behavior}

Figure 6 shows variations in tissue thickness (A) with age, and the equibiaxial mechanical responses (B) for the MFS Young and MFS Old patients. All parameters are summarized and compared in Table 3 for both the MFS Old and MFS Young groups. MFS Old patients were found to have significantly less extensible $(\mathrm{P}=0.047)$ and stiffer $(\mathrm{P}=0.029)$ tissue along the longitudinal direction. Additionally, MFS Old patients also had a significantly larger aortic diameter $(\mathrm{P}=0.037)$.

No significant correlation between patient age and tissue thickness, extensibility, anisotropy, stiffness, or aortic size was found for patients under age 40. For older patients, a statistically significant correlation between patient age and tissue thickness $(\mathrm{P}=0.004)$ and tissue stiffness along the circumferential direction in the high linear region of the curve $(\mathrm{P}=0.012)$ were found.

Figure $4 A$ and $B$ shows representative VVG images along the circumferential direction at $20 \times$ magnification for the MFS Young (A) and Old (B) groups. The MFS Old samples show more extensive elastin fiber degradation as well as straighter fibers than the younger counterpart. Additionally, as shown in Figures $5 A$ and $B$, the MFS Young samples show a larger concentration of green fibers as compared to the old.

\section{Marfan tissue exhibits diameter-independent mechanical behavior}

Figure 6 shows tissue thickness (C) and averaged equibiaxial mechanical response (D) as a function of aortic size. No statistically significant differences were found in thickness or mechanical properties for each group. Parameters are summarized in Table 4 for both the $<5$ and $>5 \mathrm{~cm}$ groups.

\section{MFS softens the effect of aneurysmal stiffening}

Figure 7 shows the averaged equibiaxial response for the age-matched TAA (average age: $52.8 \pm 4.9$ years) and MFS Old (average age: $53.3 \pm 3.7$ years) groups. All parameters are summarized and compared in Table 5. TAA samples were found to be significantly thicker $(\mathrm{P}=0.022)$, less extensible 

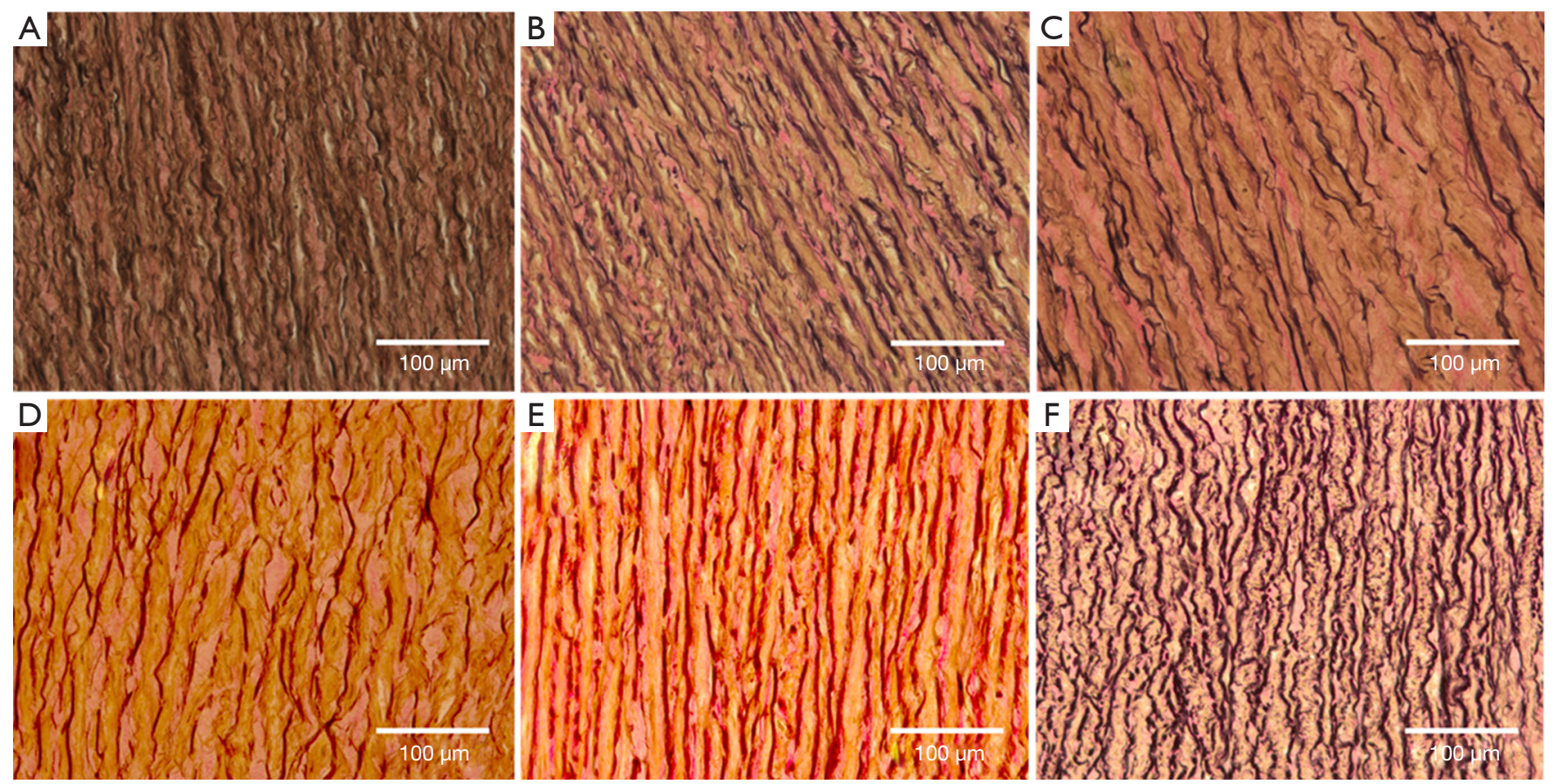

Figure 4 Representative Verhoeff-Van Gieson stains along the circumferential direction for the (A) MFS Young, (B) MFS Old, (C) TAA, (D) HH Young, (E) HH, and (F) porcine groups. Elastic fibers are shown in black, collagen in red, and other tissue elements as yellow/ brown. MFS Old, Marfan syndrome with thoracic aortic aneurysm >40 years; MFS Young, Marfan syndrome with thoracic aortic aneurysm $<40$ years; TAA, non-Marfan thoracic aortic aneurysm; Healthy human $(\mathrm{HH})$, human thoracic aortic tissue without known cardiovascular disease; Healthy human young (HH Young), human thoracic aortic tissue 54 years without known cardiovascular disease; Porcine, porcine thoracic aortic tissue without known cardiovascular disease.

in the circumferential direction $(\mathrm{P}=0.016)$, more anisotropic $(\mathrm{P}=0.031)$, and stiffer in the high linear region along the circumferential direction $(\mathrm{P}=0.049)$.

Figure $4 B$ and $C$ shows VVG images along the circumferential direction at $20 \times$ magnification for both the MFS Old (B) and TAA (C) groups. The samples show various degrees of elastin degradation, but the MFS Old elastic fibers are straighter and more densely packed than the TAA tissue. Additionally, as seen in the PicroSirius Red stain (Figure $5 B$ and $C$ ), the MFS Old tissue is made up of younger, thinner, less densely packed collagen than the TAA tissue, evidenced by the larger and more frequent interfibrillar gaps as well as the higher concentration of green fibers.

\section{TAA mechanical behavior mimics aging mechanics}

Figure 8 shows the equibiaxial response for the TAA group (average age: $52.8 \pm 4.9$ years), the aged healthy human patients (average age: $75.4 \pm 6.1$ years), an age-matched cohort of healthy human samples $(\mathrm{n}=3$, average age: $54 \pm 2.5$ years), as well as the remaining aged human samples ( $n=5$, average age: $84.4 \pm 4.7$ years).

Aside from differences in age $(\mathrm{P}=0.037)$, no statistically significant differences in the mechanical or morphological properties were found between the TAA samples and the entire cohort of healthy human patients. However, statistically significant differences were found in circumferential extensibility $(\mathrm{P}=0.008)$ and $\mathrm{DA}(\mathrm{P}=0.012)$, between the TAA group and its age-matched healthy human cohort. Additionally, there was a trend of increased stiffness in the high linear region along both the circumferential and longitudinal directions, although this was not significant ( $\mathrm{P}=0.121$ and 0.158 , respectively).

The old healthy human patient samples were found to be significantly less extensible along both the circumferential $(\mathrm{P}=0.004)$ and axial $(\mathrm{P}=0.011)$ directions, as well as stiffer in the high linear region of the curve along both directions $(\mathrm{P}=0.010)$. Additionally, compared to the TAA patients, the old human patient samples were found to be 

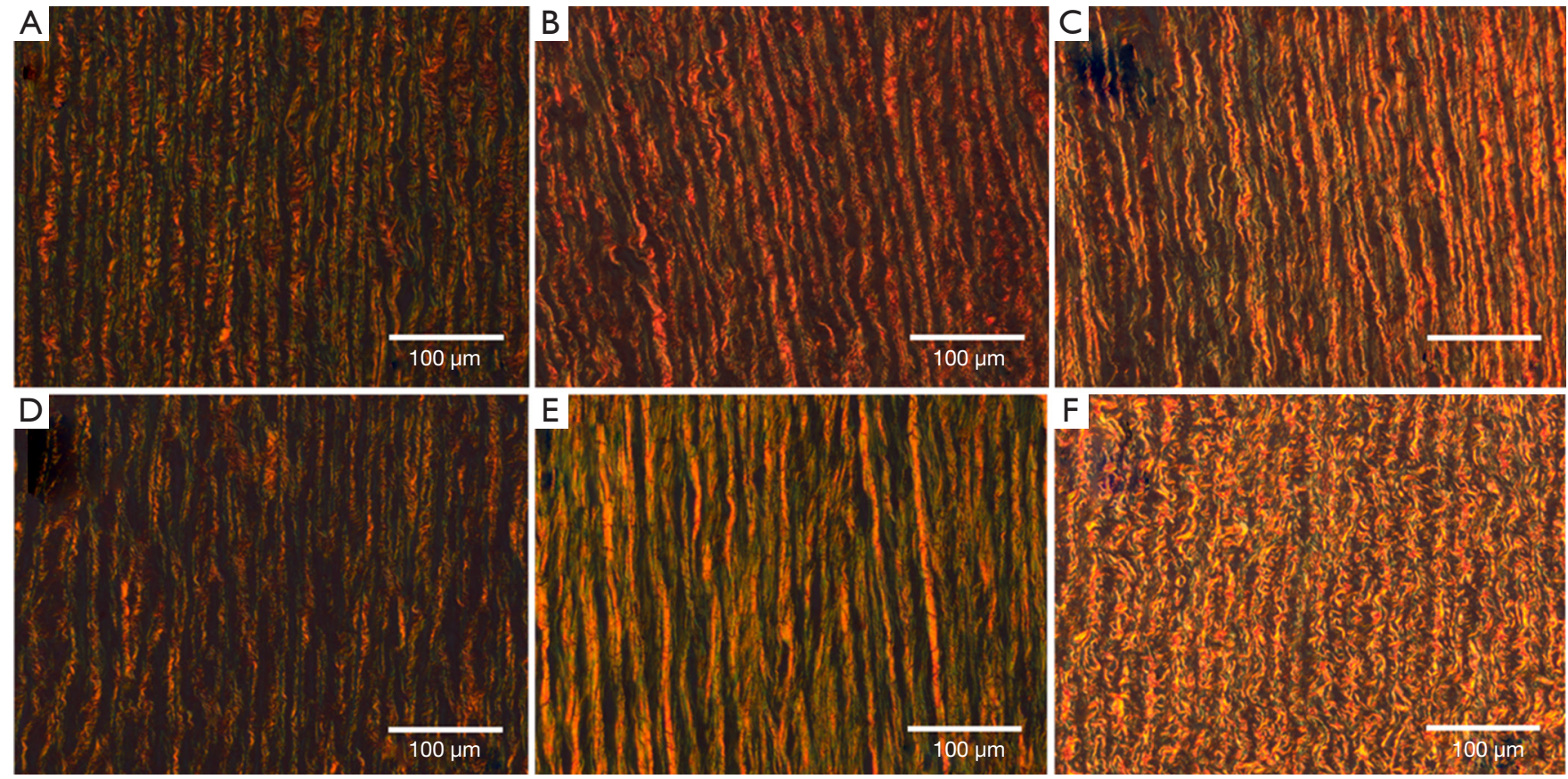

Figure 5 Representative PicroSirius Red stains along the circumferential direction for the (A) MFS Young, (B) MFS Old, (C) TAA, (D) HH Young, (E) HH, and (F) porcine groups. Newer thinner collagen is shown as green, while older thicker collagen is shown as yellow/orangered. MFS Old, Marfan syndrome with thoracic aortic aneurysm >40 years; MFS Young, Marfan syndrome with thoracic aortic aneurysm $<40$ years; TAA, Non-Marfan thoracic aortic aneurysm; Healthy human (HH), human thoracic aortic tissue without known cardiovascular disease; Healthy human young (HH Young), human thoracic aortic tissue 54 years without known cardiovascular disease; Porcine, porcine thoracic aortic tissue without known cardiovascular disease.

significantly less extensible along the longitudinal direction $(\mathrm{P}=0.007)$, and stiffer in the high linear region along both directions $(\mathrm{P}=0.011,0.022)$. Trends of increased stiffness in the low linear region were also found, although not statistically significant $(\mathrm{P}=0.083,0.108)$. All parameters and comparisons are summarized in Table 6.

Figure $4 C$-E shows representative VVG images at $20 \times$ magnification for the TAA, HH Young, and HH samples, respectively. The TAA and $\mathrm{HH}$ samples show the most extensive elastin fiber degradation, with the TAA sample also having the lowest elastin fiber density. The HH sample also had the straightest elastin fibers as compared to the $\mathrm{HH}$ Young and TAA groups. Figure 5C-E shows representative PicroSirius Red images at 20x magnification for the TAA, HH Young, and HH samples, respectively. The HH Young samples have the highest concentration of green fibers, while the TAA and HH samples had more orange fibers. Additionally, the $\mathrm{HH}$ samples had much straighter collagen fibers than the young and TAA groups.

\section{Aged porcine tissue may serve as a suitable animal} model for young MFS tissue mechanics

Figure 9 shows the equibiaxial response for the MFS Young and porcine groups, with parameters and comparisons summarized in Table 7. Aside from tissue thickness, no statistically significant differences in mechanical parameters were found.

Figure $4 A$ and $F$ shows a similar level of elastin fiber crimp, concentration, and degradation in both MFS Young and Porcine tissue, respectively. Also, as shown in Figure $5 \mathrm{~A}$ and $F$, both MFS Young and Porcine tissue shows extensive collagen crimping, although the Porcine tissue has a higher concentration of orange fibers than the MFS Young.

\section{Discussion}

\section{Statement of principal findings}

In this study, the mechanical and structural properties of 

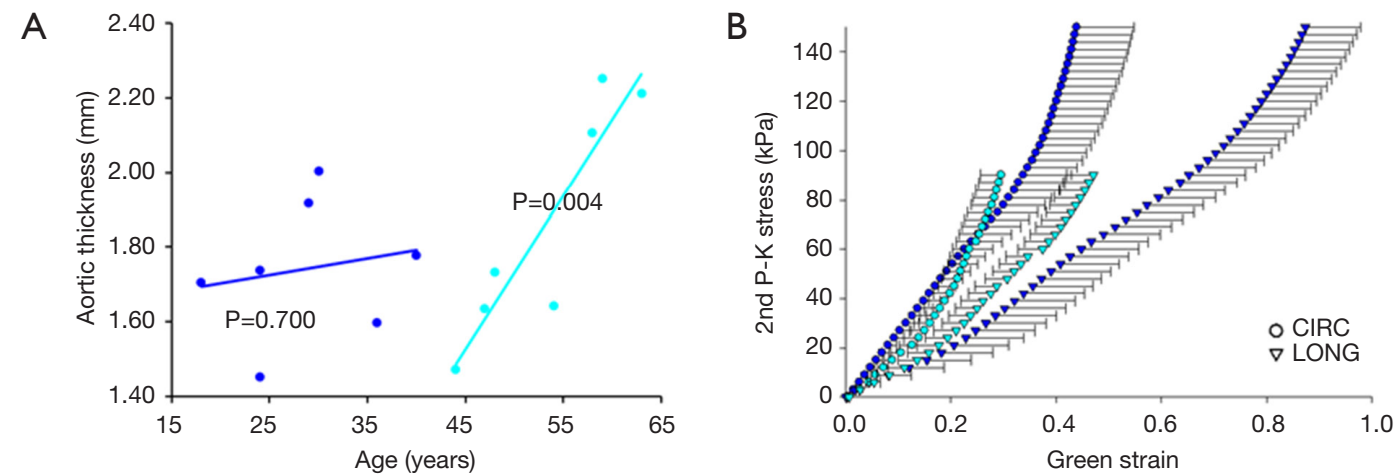

MFS Young

MFS Old
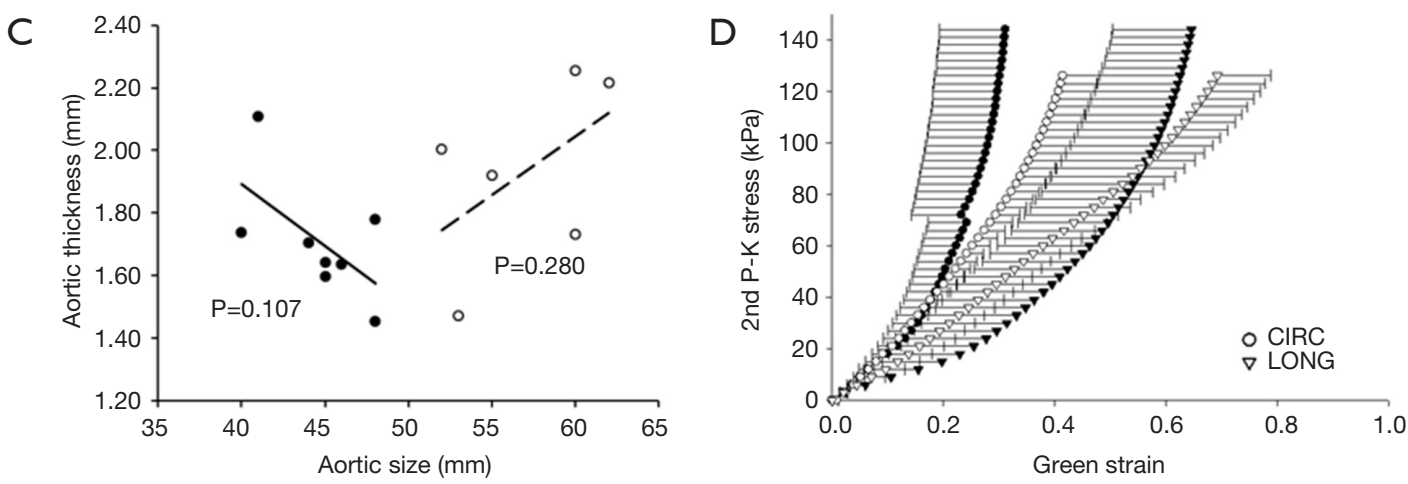

MFS $<5 \mathrm{~cm}$

MFS $>5 \mathrm{~cm}$

Figure 6 Age dependence and diameter independence of MFS properties. (A) Aortic thickness as a function of age between the MFS Old (light blue) and Young (dark blue) groups. Statistical significance taken at $\mathrm{P}<0.05$; (B) average equibiaxial response for the MFS Old (light blue) and MFS Young (dark blue) groups; (C) aortic thickness as a function of diameter between the MFS $<5 \mathrm{~cm}$ (black) and $>5 \mathrm{~cm}$ (white) groups. Statistical significance taken at $\mathrm{P}<0.05$; (D) average equibiaxial response for the $\mathrm{MFS}<5 \mathrm{~cm}$ (black) and $>5 \mathrm{~cm}$ (white) groups. MFS, Marfan syndrome.

Table 3 Comparison of mechanical and morphological parameters for the MFS Young and Old groups (Statistically significant P values are highlighted in italic)

\begin{tabular}{llll}
\hline Parameter & MFS Young & MFS Old & P value \\
\hline Age (years) & $28.50 \pm 3.36$ & $53.29 \pm 2.69$ & $2.1 \times 10^{-5}$ \\
\hline Aortic size $(\mathrm{mm})$ & $46.70 \pm 2.06$ & $52.43 \pm 3.21$ & 0.037 \\
\hline Thickness $(\mathrm{mm})$ & $1.70 \pm 0.07$ & $1.87 \pm 0.12$ & 0.004 \\
\hline EXT long & $0.53 \pm 0.15$ & $0.43 \pm 0.09$ & 0.041 \\
\hline EXT circ & $0.27 \pm 0.10$ & $0.25 \pm 0.04$ & 0.298 \\
\hline DA & $0.50 \pm 0.90$ & $0.64 \pm 0.06$ & 0.191 \\
\hline TM long low $(\mathrm{kPa})$ & $155.59 \pm 42.11$ & $154.62 \pm 35.14$ & 0.465 \\
\hline TM long high $(\mathrm{kPa})$ & $803.15 \pm 316.40$ & $1,917.57 \pm 653.97$ & 0.029 \\
\hline TM circ low $(\mathrm{kPa})$ & $353.65 \pm 109.42$ & $193.97 \pm 54.33$ & 0.097 \\
\hline TM circ high $(\mathrm{kPa})$ & $4,112.64 \pm 2,097.59$ & $1,772.53 \pm 533.19$ & 0.012 \\
\hline MFS, Marfan syndrome; EXT, extensibility; circ, circumferential direction; long, longitudinal direction; DA, degree of anisotropy; TM, tangent modulus.
\end{tabular}




\begin{tabular}{|c|c|c|c|}
\hline Parameter & $\mathrm{MFS}<5 \mathrm{~cm}$ & $\mathrm{MFS}>5 \mathrm{~cm}$ & $P$ value \\
\hline Sample size & 8 & 6 & - \\
\hline Age (years) & $37.63 \pm 5.24$ & $45.50 \pm 5.80$ & 0.168 \\
\hline Aortic size $(\mathrm{mm})$ & $44.63 \pm 1.03$ & $57.00 \pm 1.71$ & $1.41 \times 10^{-5}$ \\
\hline Thickness (mm) & $1.71 \pm 0.07$ & $1.93 \pm 0.12$ & 0.249 \\
\hline EXT long & $0.56 \pm 0.12$ & $0.39 \pm 0.07$ & 0.141 \\
\hline EXT circ & $0.31 \pm 0.07$ & $0.22 \pm 0.07$ & 0.327 \\
\hline DA & $0.59 \pm 0.05$ & $0.60 \pm 0.11$ & 0.386 \\
\hline TM long low (kPa) & $153.56 \pm 31.97$ & $161.27 \pm 40.09$ & 0.441 \\
\hline TM long high $(\mathrm{kPa})$ & $1,512.72 \pm 608.27$ & $1,273.64 \pm 368.42$ & 0.046 \\
\hline TM circ low (kPa) & $234.47 \pm 42.26$ & $294.37 \pm 124.30$ & 0.292 \\
\hline TM circ high (kPa) & $2,798.36 \pm 1,268.80$ & $3,367.92 \pm 1,521.11$ & 0.337 \\
\hline
\end{tabular}

MFS, Marfan syndrome; EXT, extensibility; circ, circumferential direction; long, longitudinal direction; DA, degree of anisotropy; TM, tangent modulus.

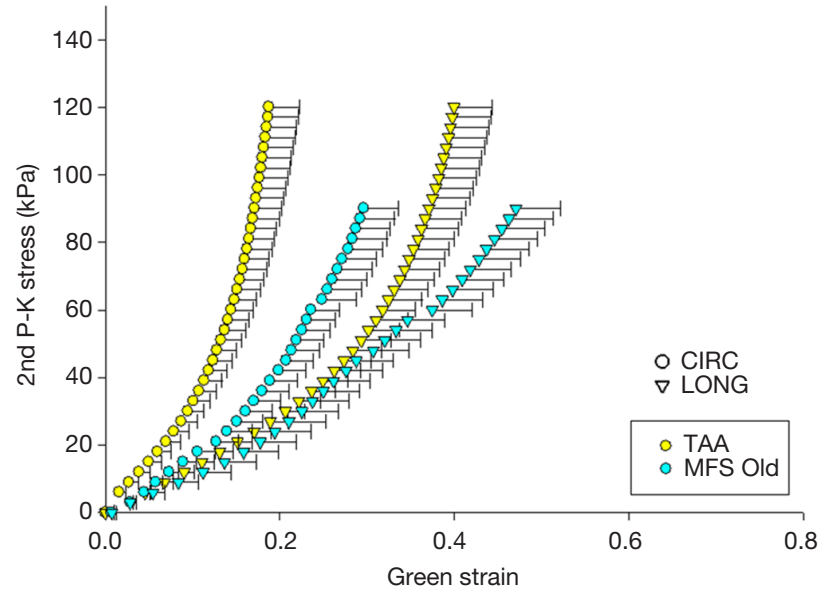

Figure 7 Average equibiaxial response for the TAA (yellow) and MFS Old (light blue) groups. MFS Old, Marfan syndrome with thoracic aortic aneurysm $>40$ years; TAA, non-Marfan thoracic aortic aneurysm.

MFS thoracic aortic tissue was investigated based on age, aneurysmal, and genetic condition effects. In MFS patients, aging was found to be a greater determinant of arterial deterioration than aortic size, which was not found to be a significant determining factor. Both age and aneurysmal condition are shown as stiffening factors in aortic tissue; TAA patients exhibited a stiffer mechanical response than their age-matched healthy human counterparts, but resembled the mechanical response of the significantly older cohort of all human patients in good cardiovascular health.

Interestingly, aneurysmal tissue without the MFS condition was found to be stiffer than its age-matched MFS counterpart, possibly owing to the lower density of medial elastin fibers and reduction of the low linear region, leading to earlier engagement of collagen and transition of the mechanical response.

Aged porcine tissue was found to have similar mechanical behavior and structural properties as the young MFS patients.

\section{Discussion of principal findings in relation to other studies}

\section{In vivo}

Significant effort has been devoted to the investigation of the mechanical properties and pathogenesis of AsAA tissue (7,13,14,18-21); however, MFS-specific studies are scarce. A number of in vivo studies on Marfan tissues investigate aortic distensibility, stiffness index, and pulse wave velocity $(3,8-12)$, consistently finding increased aortic diameter (12), decreased distensibility $(8-10)$, and stiffness $(8,9,12)$ in MFS patients compared to age- and gender-matched controls; however, these parameters were not correlated, as also found in our study. Unfortunately, in vivo studies are limited 


\begin{tabular}{|c|c|c|c|}
\hline Parameter & TAA & MFS Old & $P$ value \\
\hline Age (years) & $57.29 \pm 4.83$ & $53.29 \pm 2.69$ & 0.242 \\
\hline Aortic size (mm) & $62.80 \pm 7.49$ & $52.43 \pm 3.21$ & 0.093 \\
\hline Thickness (mm) & $2.24 \pm 0.17$ & $1.87 \pm 0.12$ & 0.022 \\
\hline EXT long & $0.30 \pm 0.04$ & $0.43 \pm 0.09$ & 0.102 \\
\hline EXT circ & $0.13 \pm 0.02$ & $0.25 \pm 0.04$ & 0.016 \\
\hline DA & $0.47 \pm 0.06$ & $0.64 \pm 0.06$ & 0.031 \\
\hline TM long low (kPa) & $147.07 \pm 23.26$ & $154.62 \pm 35.14$ & 0.272 \\
\hline TM long high $(\mathrm{kPa})$ & $1,367.28 \pm 218.81$ & $1,917.57 \pm 653.97$ & 0.412 \\
\hline TM circ low (kPa) & $329.73 \pm 89.44$ & $193.97 \pm 54.33$ & 0.085 \\
\hline TM circ high $(\mathrm{kPa})$ & $3,729.69 \pm 926.88$ & $1,772.53 \pm 533.19$ & 0.049 \\
\hline
\end{tabular}

MFS, Marfan syndrome; TAA, non-Marfan thoracic aortic aneurysm; EXT, extensibility; circ, circumferential direction; long, longitudinal direction; DA, degree of anisotropy; TM, tangent modulus.

to investigating only the physiological range and are not able to study parameters such as failure criteria.

\section{Ex vivo}

To our knowledge, few publications have studied the ex vivo mechanical behavior of MFS tissue (13-15). Okamoto et al. compared the planar equibiaxial mechanical response of aortic tissue from age-matched MFS and BAV patients, but did not report significant differences in their distensibility. Uniaxially, higher elastic modulus and maximum stress in the thoracic aortic tissue of MFS patients were found as compared to healthy controls (15). The Jaharri study found maximum stress values of $\sim 1.5 \mathrm{MPa}$ along the circumferential direction, similar to the $1.3 \mathrm{MPa}$ average found in the current study; Jaharri also reports higher UTS values in the MFS patients than the TAA group, correlating with our results.

\section{Aneurysmal stiffening}

In this study, thoracic aortic aneurysms were also found to be associated with stiffening. Fifty-three years old TAA patients were found to have similar mechanical behavior as the 75-year-old healthy group, but reached higher equibiaxial stress and UTS values. Compared to the agematched controls, TAA patients had stiffer mechanical behavior, but similar equibiaxial stress and UTS values. Taken together, these findings indicate that despite stiffening, the aneurysmal condition is not necessarily associated with weakening of aortic tissue, as also found by
Iliopoulos et al. (18). Studies investigating the mechanical properties of ascending aortic aneurysm tissue found stiffening compared to age-matched controls $(7,22)$, agreeing with the current study.

In addition to aneurysmal-related stiffening as reported in in vivo and ex vivo studies, our study also found agematched MFS patients to have significant tissue weakening in comparison to their TAA and healthy counterparts. Additionally, Pham et al. found BAV patients, which have been structurally and mechanically linked to MFS patients $(13,14,23)$, to have significantly more isotropic aortic tissue than other AsAA patients, as also found in MFS patients in the current study (24). Pham also found a trend of age-related thickening in BAV tissue, agreeing with our MFS findings.

\section{Aging}

Aging is known to be the single greatest risk factor for the development of cardiovascular diseases (25). In the current study, the MFS patients were divided into young and old based on diagnostic criteria which report 40 years as the cutoff age for major cardiovascular events (1). Significant differences were found in the morphological and mechanical properties of younger and older MFS tissue, showing stiffening, weakening, and thickening of thoracic tissue. While this was also evident in the healthy controls, aortic stiffening of a similar degree was not evident in patients under 60 years of age, similar to the AHA 65 years cutoff (16). 

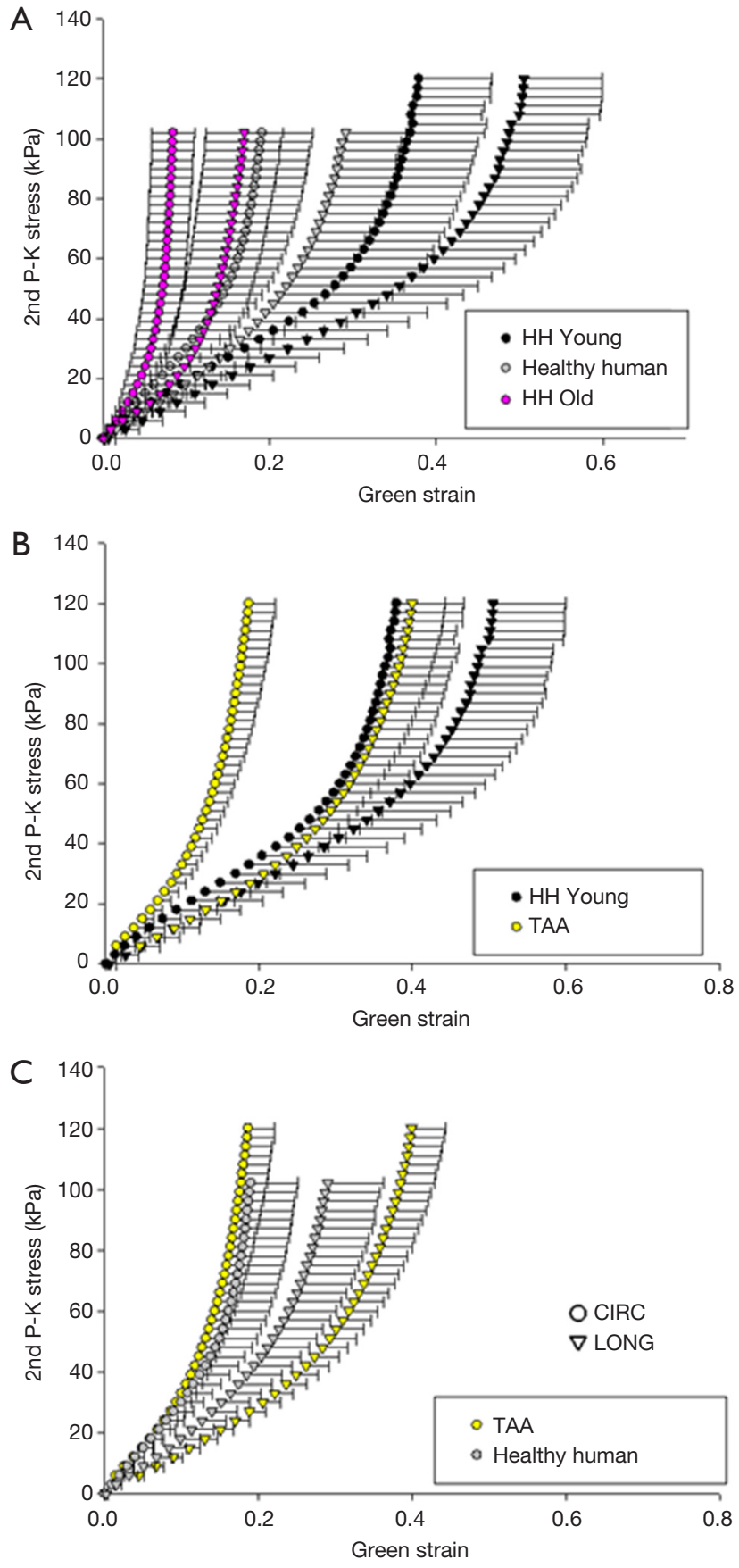

Figure 8 Average equibiaxial responses for (A) all healthy human patients (gray) as well by age (young: black; old: pink); (B) TAA (yellow) and HH Young (black) groups; (C) TAA (yellow) and $\mathrm{HH}$ (gray) groups. TAA, non-Marfan thoracic aortic aneurysm; Healthy human $(\mathrm{HH})$, human thoracic aortic tissue without known cardiovascular disease; Healthy human young (HH Young), Human thoracic aortic tissue $\sim 54$ years without known cardiovascular disease; Healthy human old (HH Old), human thoracic aortic tissue $\sim 84$ years without known cardiovascular disease.
Aortic size: aortic diameter did not significantly correlate with mechanical and morphological tissue properties in this study, agreeing with recently published results $(7,18)$. Current guidelines recommend surgical intervention at an aortic diameter greater than $5.5 \mathrm{~cm}, 5.0 \mathrm{~cm}$ for MFS patients (26,27); similarly, Pape et al. show that type A dissections occur at a mean diameter of $5.31 \mathrm{~cm}$, below the $5.5 \mathrm{~cm}$ cutoff (28). Additionally, Coady et al. (29) and Davies et al. (30) even show an increased risk of complications at aortic sizes smaller than $4 \mathrm{~cm}$ for descending TAAs, well under the $5.5 \mathrm{~cm}$ cutoff, also supported by the similar mean 5 -year survival rates for patients with $4.0-5.9 \mathrm{~cm}$ aortic diameters (31).

\section{Structure}

As shown in the presented results, degradation of the elastin fibers was observed in the MFS and TAA tissue, also consistent with previously published findings (32-34). In addition to elastin degradation, higher interfibrillar spaces, and decreased elastin fiber concentration have been documented (32-34), supporting our results. Collagen fiber composition and concentration were not found to be affected in the TAA and MFS conditions $(33,35)$; however, studies also show increased rates of collagen synthesis and turnover in MFS patients (34). These results also agree with our findings, as evidenced by the observed increase of newer, thinner collagen in the MFS groups as compared to the TAA and the age-matched healthy controls. Also agreeing with previously published results (36-38), agedependent differences in the collagen fibers were found, showing decreased crimping and interfibrillar spacing in older MFS, HH, and TAA patients.

\section{Weakness and limitations}

A larger sample size would provide higher statistical power. Additionally, the circumferential and longitudinal directions of the MFS samples were determined by visual inspection, possibly affecting results. However, the MFS results obtained in this study are consistent with other ex vivo studies $(14,15,24)$ and thus the visual judgment of axial and circumferential directions is not believed to have significantly affected the results presented herein. Lastly, quantitative microstructural analysis may provide additional support for the presented histological findings.

\section{Generalizability to other populations and implications for clinicians and policymakers}

These results provide additional insight into current clinical 


\begin{tabular}{|c|c|c|c|c|c|c|c|}
\hline Parameter & TAA & Healthy human & $\begin{array}{l}\mathrm{P} \text { value (TAA } \\
\text { vs. } \mathrm{HH})\end{array}$ & $\begin{array}{l}\text { Healthy human } \\
\text { Young }\end{array}$ & $\begin{array}{l}P \text { value (TAA } \\
\text { vs. Young) }\end{array}$ & $\begin{array}{l}\text { Healthy human } \\
\text { Old }\end{array}$ & $\begin{array}{l}\text { P value } \\
\text { (TAA vs. Old) }\end{array}$ \\
\hline Sample size & 8 & 8 & - & 3 & - & 5 & - \\
\hline Age (years) & $52.80 \pm 4.89$ & $75.44 \pm 6.05$ & 0.037 & $54.00 \pm 2.52$ & 0.342 & $84.40 \pm 4.68$ & 0.002 \\
\hline Aortic size (mm) & $62.80 \pm 7.49$ & - & - & - & - & - & - \\
\hline Thickness (mm) & $2.24 \pm 0.17$ & $2.07 \pm 0.12$ & 0.272 & $2.36 \pm 0.10$ & 0.345 & $1.98 \pm 0.16$ & 0.137 \\
\hline EXT long & $0.30 \pm 0.04$ & $0.22 \pm 0.06$ & 0.159 & $0.38 \pm 0.08$ & 0.160 & $0.13 \pm 0.04$ & 0.007 \\
\hline EXT Circ & $0.13 \pm 0.02$ & $0.15 \pm 0.06$ & 0.336 & $0.29 \pm 0.06$ & 0.008 & $0.07 \pm 0.03$ & 0.067 \\
\hline DA & $0.47 \pm 0.06$ & $0.63 \pm 0.01$ & 0.060 & $0.73 \pm 0.04$ & 0.012 & $0.57 \pm 0.11$ & 0.211 \\
\hline TM long low (kPa) & $147.07 \pm 23.26$ & $345.74 \pm 0.05$ & 0.170 & $152.60 \pm 37.31$ & 0.432 & $461.62 \pm 251.63$ & 0.104 \\
\hline TM long high (kPa) & $1,367.28 \pm 218.81$ & $2,293.74 \pm 0.07$ & 0.142 & $969.62 \pm 226.77$ & 0.139 & $3,088.21 \pm 840.05$ & 0.212 \\
\hline TM circ low ( $\mathrm{kPa})$ & $329.73 \pm 89.44$ & $462.72 \pm 161.12$ & 0.488 & $192.41 \pm 51.33$ & 0.196 & $624.91 \pm 236.98$ & 0.108 \\
\hline TM circ high $(\mathrm{kPa})$ & $3,729.69 \pm 926.88$ & $4,956.17 \pm 638.61$ & 0.199 & $1,854.80 \pm 842.39$ & 0.121 & $6,817.00 \pm 481.98$ & 0.011 \\
\hline
\end{tabular}

TAA, non-Marfan thoracic aortic aneurysm; HH, healthy human; EXT, extensibility; circ, circumferential direction; DA, degree of anisotropy; TM, tangent modulus.

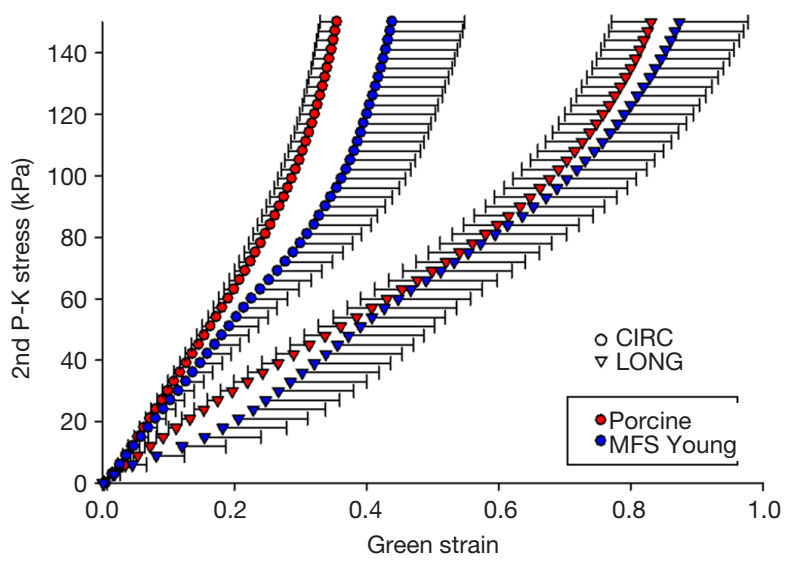

Figure 9 Average equibiaxial response for the porcine (red) and MFS Young (dark blue) groups. MFS Young, Marfan syndrome with thoracic aortic aneurysm $<40$ years; Porcine, porcine thoracic aortic tissue without known cardiovascular disease.

trends regarding thoracic aortic aneurysms, focusing on the genetic predisposition of MFS. Regarding age, our results support the Ghent diagnostic criteria, with the age of 40 being a significant predictor for the onset of mechanical and structural deterioration of the thoracic aorta. Additionally, the MFS condition was found to accelerate aortic stiffening and weakening as compared to its TAA counterparts, further supporting the earlier need for intervention. Regarding aortic size, the results of this study also support current trends, indicating that an aortic size greater than $5.0 \mathrm{~cm}$ does not necessarily correlate with mechanical deterioration, and that other factors such as age may be more powerful indicators of disease onset and progression. In conclusion, these findings indicate that current aneurysmal diagnostic criteria based on aortic size do not provide sufficient indication of dissection or rupture potential.

\section{Unanswered questions and future research}

This study sheds light on the age-dependent mechanical properties of MFS patients as compared to healthy and non-MFS aneurysmal controls. However, much remains to be investigated. The mechanical and structural similarity of younger MFS and older porcine aortic tissue found in this study may provide a useful animal model for the continued mechanical investigation through experiments or computational approaches for future studies.

Of particular interest for future studies is the physiological basis behind diameter independent aneurysm onset and progression. Future work should focus on investigating cellular mechanisms in order to better understand aneurysmal remodeling and their long-term effects. 


\begin{tabular}{|c|c|c|c|}
\hline Parameter & MFS Young & Porcine & $P$ value \\
\hline Age (years) & $28.50 \pm 3.36$ & $1-5$ & - \\
\hline Aortic size (mm) & $46.67 \pm 2.06$ & - & - \\
\hline Thickness (mm) & $1.74 \pm 0.07$ & $2.77 \pm 0.07$ & $<0.001$ \\
\hline EXT long & $0.54 \pm 0.13$ & $0.58 \pm 0.04$ & 0.367 \\
\hline EXT circ & $0.30 \pm 0.09$ & $0.23 \pm 0.02$ & 0.181 \\
\hline DA & $0.55 \pm 0.09$ & $0.46 \pm 0.04$ & 0.150 \\
\hline TM long low (kPa) & $159.10 \pm 35.76$ & $142.84 \pm 12.62$ & 0.316 \\
\hline TM long high (kPa) & $902.95 \pm 285.42$ & $611.70 \pm 47.41$ & 0.124 \\
\hline TM circ low (kPa) & $326.32 \pm 96.43$ & $336.24 \pm 21.76$ & 0.159 \\
\hline TM circ high (kPa) & $3,873.76 \pm 1,788.81$ & $1,274.27 \pm 160.99$ & 0.304 \\
\hline
\end{tabular}

Moreover, the results presented herein provide a starting point for computational investigations of MFS, TAA, and healthy human aortic tissue, in order to better understand the underlying mechanical environment in each disease condition and provide patient-specific investigation regarding the onset and progression of thoracic aortic dilation in each case.

\section{Acknowledgements}

We would like to thank Giji Joseph, John Wilson, Sydney Platt, and Mynah Holloway for their experimental and data analysis support.

Funding: This research was funded in part by the NIH HL 104080 grant.

\section{Footnote}

Conflicts of Interest: The authors have no conflicts of interest to declare.

\section{References}

1. Judge DP, Dietz HC. Marfan's syndrome. Lancet 2005;366:1965-76.

2. Castellano JM, Silvay G, Castillo JG. Marfan Syndrome: Clinical, Surgical, and Anesthetic Considerations. Semin Cardiothorac Vasc Anesth 2014;18:260-71.

3. Nollen GJ, Groenink M, Tijssen JG, et al. Aortic stiffness and diameter predict progressive aortic dilatation in patients with Marfan syndrome. Eur Heart J 2004;25:1146-52.

4. Murdoch JL, Walker BA, Halpern BL, et al. Life expectancy and causes of death in the Marfan syndrome. $\mathrm{N}$ Engl J Med 1972;286:804-8.

5. Silverman DI, Burton KJ, Gray J, et al. Life expectancy in the Marfan syndrome. Am J Cardiol 1995;75:157-60.

6. Loeys BL, Dietz HC, Braverman AC, et al. The revised Ghent nosology for the Marfan syndrome. J Med Genet 2010;47:476-85.

7. Vorp DA, Schiro BJ, Ehrlich MP, et al. Effect of aneurysm on the tensile strength and biomechanical behavior of the ascending thoracic aorta. Ann Thorac Surg 2003;75:1210-4.

8. Hirata K, Triposkiadis F, Sparks E, et al. The Marfan syndrome: abnormal aortic elastic properties. J Am Coll Cardiol 1991;18:57-63.

9. Jeremy RW, Huang H, Hwa J, et al. Relation between age, arterial distensibility, and aortic dilatation in the Marfan syndrome. Am J Cardiol 1994;74:369-73.

10. Groenink M, de Roos A, Mulder BJ, et al. Biophysical Properties of the Normal-sized Aorta in Patients with Marfan Syndrome: Evaluation with MR Flow Mapping 1. Radiology 2001;219:535-40.

11. Savolainen A, Keto P, Hekali P, et al. Aortic distensibility in children with the Marfan syndrome. Am J Cardiol 1992;70:691-3.

12. Sonesson B, Hansen F, Länne T. Abnormal mechanical properties of the aorta in Marfan's syndrome. Eur J Vasc Surg 1994;8:595-601. 
13. Okamoto RJ, Wagenseil JE, DeLong WR, et al. Mechanical properties of dilated human ascending aorta. Ann Biomed Eng 2002;30:624-35.

14. Okamoto RJ, Xu H, Kouchoukos NT, et al. The influence of mechanical properties on wall stress and distensibility of the dilated ascending aorta. J Thorac Cardiovasc Surg 2003;126:842-50.

15. Jarrahi A, Karimi A, Navidbakhsh M, et al. Experimental/ numerical study to assess mechanical properties of healthy and Marfan syndrome ascending thoracic aorta under axial and circumferential loading. Materials Technology 2016;31:247-54.

16. Nishimura RA, Otto CM, Bonow RO, et al. 2014 AHA/ ACC guideline for the management of patients with valvular heart disease: Executive summary: A report of the American college of cardiology/American heart association task force on practice guidelines. J Am Coll Cardiol 2014;63:2438-88.

17. Sacks MS, Sun W. Multiaxial mechanical behavior of biological materials. Annu Rev Biomed Eng 2003;5:251-84.

18. Iliopoulos DC, Kritharis EP, Giagini AT, et al. Ascending thoracic aortic aneurysms are associated with compositional remodeling and vessel stiffening but not weakening in agematched subjects. J Thorac Cardiovasc Surg 2009;137:101-9.

19. Pasta S, Phillippi JA, Gleason TG, et al. Effect of aneurysm on the mechanical dissection properties of the human ascending thoracic aorta. J Thorac Cardiovasc Surg 2012;143:460-7.

20. Pasta S, Rinaudo A, Luca A, et al. Difference in hemodynamic and wall stress of ascending thoracic aortic aneurysms with bicuspid and tricuspid aortic valve. J Biomech 2013;46:1729-38.

21. Koullias G, Modak R, Tranquilli M, et al. Mechanical deterioration underlies malignant behavior of aneurysmal human ascending aorta. J Thorac Cardiovasc Surg 2005;130:677.e1-e9.

22. García-Herrera CM, Atienza J, Rojo F, et al. Mechanical behaviour and rupture of normal and pathological human ascending aortic wall. Med Biol Eng Comput 2012;50:559-66.

23. Grewal N, Franken R, Mulder BJ, et al. Histopathology of aortic complications in bicuspid aortic valve versus Marfan syndrome: relevance for therapy? Heart Vessels 2016;31:795-806.

24. Pham T, Martin C, Elefteriades J, et al. Biomechanical characterization of ascending aortic aneurysm with concomitant bicuspid aortic valve and bovine aortic arch. Acta Biomater 2013;9:7927-36.

25. Cheng HM, Park S, Huang Q, et al. Vascular aging and hypertension: Implications for the clinical application of central blood pressure. Int J Cardiol 2017;230:209-13.

26. Saliba E, Sia Y. The ascending aortic aneurysm: When to intervene? IJC Heart Vasculature 2015;6:91-100.

27. Nataf P, Lansac E. Dilation of the thoracic aorta: medical and surgical management. Heart 2006;92:1345-52.

28. Pape LA, Tsai TT, Isselbacher EM, et al. Aortic diameter $\geq$ $5.5 \mathrm{~cm}$ is not a good predictor of type A aortic dissection. Circulation 2007;116:1120-7.

29. Coady MA, Rizzo JA, Hammond GL, et al. Surgical intervention criteria for thoracic aortic aneurysms: a study of growth rates and complications. Ann Thorac Surg 1999;67:1922-6.

30. Davies RR, Goldstein LJ, Coady MA, et al. Yearly rupture or dissection rates for thoracic aortic aneurysms: simple prediction based on size. Ann Thorac Surg 2002;73:17-27; discussion 27-8.

31. Elefteriades JA, Rizzo JA, Coady MA. Thoracic Aorta. Radiology 1999;211:889.

32. Halme T, Savunen T, Aho H, et al. Elastin and collagen in the aortic wall: changes in the Marfan syndrome and annuloaortic ectasia. Exp Mol Pathol 1985;43:1-12.

33. Abraham PA, Perejda A, Carnes W, et al. Marfan syndrome. Demonstration of abnormal elastin in aorta. J Clin Invest 1982;70:1245.

34. Tsamis A, Krawiec JT, Vorp DA. Elastin and collagen fibre microstructure of the human aorta in ageing and disease: a review. J R Soc Interface 2013;10:20121004.

35. Perejda AJ, Abraham P, Carnes WH, et al. Marfan's syndrome: structural, biochemical, and mechanical studies of the aortic media. J Lab Clin Med 1985;106:376-83.

36. Schlatmann TJ, Becker AE. Histologic changes in the normal aging aorta: implications for dissecting aortic aneurysm. Am J Cardiol 1977;39:13-20.

37. Faber M, Moller-Hou G. The human aorta. V. Collagen and elastin in the normal and hypertensive aorta. Acta Pathol Microbiol Scand 1952;31:377-82.

38. Greenberg SR. The association of medial collagenous tissue with atheroma formation in the aging human aorta as revealed by a special technique. Histol Histopathol 1986;1:323-6.

Cite this article as: Sulejmani F, Pokutta-Paskaleva A, Ziganshin B, Leshnower B, Iannucci G, Elefteriades J, Sun W. Biomechanical properties of the thoracic aorta in Marfan patients. Ann Cardiothorac Surg 2017;6(6):610-624. doi: 10.21037/acs.2017.09.12 